\title{
Antioxidant and Antioxidant capacity of raw and processed Nigerian Beetroot (Beta vulgaris)
}

*Fidelis E. Olumese and Henrietta A. Oboh

Department of Medical Biochemistry, School of Basic Medical Science, College of Medicine, University of Benin, Benin City, Edo state, Nigeria.

[ ${ }^{\star}$ Corresponding author: Email: fidelisolumese@yahoo.com; : : +234-8023538551]

\begin{abstract}
Raw and processed Beetroot (Beta vulgaris) were assessed for the natural antioxidants; Total phenol, flavonoids, vitamin C using Folin-Ciocalteau, potassium acetate and dinitophenyl hydrazine. The antioxidant radical scavenging abilities were evaluated using 2,2'-azino-bis (3-ethylbenzthiazoline-6-sulphonic acid) [ABTS] and ferric reducing antioxidant property [FRAP] respectively. Raw beetroots and the beetroot juice contained the highest amount of total phenol $(98.08 . \pm 8.16 \mathrm{mg} / \mathrm{g}$ and $98.08 . \pm 5.77 \mathrm{mg} / \mathrm{GAE} / \mathrm{g}$ ) respectively. Oven dried beetroot have the lowest value for total phenol $(94.23 \pm 2.72 \mathrm{mg} / \mathrm{GAE} / \mathrm{g}$. The heat treated beetroot had the highest flavonoids of $96.67 \pm 10.10 \mathrm{mgGE} / \mathrm{g}$. Flavonoids were lowest for the raw beetroot $(63.34 \pm 4.72 \mathrm{mg} / \mathrm{QE} / \mathrm{g})$. Oven dried and Beetroot juice have a total flavonoid value of $83.34 \pm 4.471 \mathrm{mg} / \mathrm{GE} / \mathrm{g}$ and $83.34 \pm 3.34 \mathrm{mg} / \mathrm{GE} / \mathrm{g}$ respectively. Vitamin $\mathrm{C}$ content was highest in Beetroot juice $(44.34 \pm 2.84 \mathrm{mgAAE} / \mathrm{g})$ and lowest in heat treated beetroot $(30.18 \pm 0.61 \mathrm{mgAAE} / \mathrm{g})$. Heat treated Beetroot have the highest value for ABTS scavenging ability. FRAP value $(33.33 \pm 0.00)$ was highest in oven dried beetroot. Raw Beetroot and its juice possess significant antioxidant and radical scavenging abilities which correlated positively with the natural antioxidants. Heat treatment however, increased the flavonoids present in the beetroot samples with a corresponding increase in the ABTS and FRAP scavenging abilities $(19.85 \pm 4.15$ and $33.33 \pm 0.00)$ respectively. Beetroot in its natural and processed form is a rich source of antioxidants and free antioxidants scavenging abilities
\end{abstract}

Keywords: Antioxidants, Antioxidant capacity, free radicals, Beetroots

\section{INTRODUCTION}

Beetroot (Beta vulgaris) vegetables of the chenopodiaceace family (Hill and Langer, 1991). It is widely consumed in traditional western cooking but rarely used in West Africa (Grubben and Denton, 2004). It can be eaten as a cooked vegetable; by using different types of heat treatment or extracted for its juice to make Beetroot juice (Wotton-Beard and Ryan, 2011). The natural and harmless pigments are also useful in the food industry (Esatbeyoglu et al., 2015). Beetroot is a rich source nutrients. The vitamins include folic acid, vitamins $A$ and $C$, vitamin $B 6$, niacin, and biotin. The minerals content are iron, magnesium, selenium, potassium, calcium, zinc, phosphorus, and sodium (Straus et al., 2013). The bioactive compounds includes phenolic compounds, saponins, and especially betalains, which are responsible for the characteristic color of this tuber (Zielinska-Przyjemska et al., 2009). In recent years, there has been growing interest in the biological activity of red Beetroot (Beta vulgaris rubra) Beetroot can be utilised as an inexpensive neutraceutical supplement to promote health (Clifford et al., 2015). It has been reported to be effective in managing hypertension and improve cardiac function (Salloum et al., 2015; Bondonno et al., 2015). This has made Beetroot to be used as an adjuvant with other orthodox medicine because it has antiviral and anti microbial effects(Strack et al.. 2003), antioxidant and anti-inflammatory properties (Georgiev,2010; Zielińska-Przyjemska et al., 2012), inhibition of human tumor cell proliferation (Lechner,2010; Zhang et al., 2013) and hepatoprotective effects (Rabeh, 2015).

This study was carried out to investigate the antioxidant and antioxidant capacity of raw and processed Nigerian red Beetroots for its potential as a functional food.

\section{MATERIALS AND METHODS \\ Sample}

Beetroots (Beta vulgaris) were purchased from the Vegetable market, Airport Road, Benin City, Edo State, Nigeria. The Beetroots were kept at room temperature until utilised.

\section{Preparation of samples}

The Beetroot was washed to remove sand, dirt, debris and peeled. The peeled beetroots were then processed.

\section{Preparation of Beetroot juice}

Ten grammes $(10 \mathrm{gms})$ of the peeled beetroot were blended with $50 \mathrm{ml}$ of distilled water in an electronic blender (Saisho S-423 electric blender) to get a 
uniform consistency slurry. The slurry was poured into a measuring cylinder and the volume was made up to $100 \mathrm{ml}$ using distilled water. Therefore the solution was $10 \mathrm{~g} / 100 \mathrm{ml}(10 \%)$. The solution was centrifuged using low speed centrifuge KX2400C for 10 mins at $500 \mathrm{rpm}$. The supernatant was collected and stored in plastic bottles. All the supernatants were stored in a refrigerator at $0^{\circ} \mathrm{C}$ until utilized within twenty four hours.

\section{Raw Beetroot}

The peeled beetroot was grated with a kitchen grater and transferred to a sieve. The excess water from the beetroot was drained and air dried to constant weight. The dried sample was grounded into a powder. The powdered sample was stored in a clean dry plastic container at room temperature until analysed

\section{Heat treated Beetroot}

The peeled beetroot was grated and transferred to a sieve which was then placed in a boiling pot of water at $100^{\circ} \mathrm{C}$ for fifteen minutes. The heat treated sample was strained to remove excess water and dried in an oven DHG- UK at $40^{\circ} \mathrm{C}$ to a constant weight. The dried sample was then grounded into a powder. The powdered sample was stored in a clean dry plastic container at room temperature until analysed

\section{Oven dried Beetroot}

The peeled beetroot was grated and transferred to a sieve. The sample was strained to remove excess water and dried in an oven DHG- UK at $40^{\circ} \mathrm{C}$ to a constant weight. The dried sample was then grounded into a powder and stored in a clean dry plastic container at $0^{\circ} \mathrm{C}$ until analysed within twenty four hours.

\section{Evaluation of Antioxidant Activity 2,2'-azino-bis(3-ethylbenzthiazoline-6-sulphonic acid) [ABTS] Radical Scavenging Ability}

The ABTS scavenging ability of the extracts was determined according to the method described by Re et al. (1999). The ABTS radical was generated by reacting ABTS aqueous solution $(7 \mathrm{mmol} / \mathrm{l})$ with $\mathrm{K}_{2} \mathrm{~S}_{2} \mathrm{O}_{8}$ (2.45mmol//, final concentration) in the dark for $16 \mathrm{~h}$ and adjusting the Absorbance at $734 \mathrm{~nm}$ to 0.700 with ethanol. A stock solution of $1 \mathrm{gm} / 10 \mathrm{ml}$ distilled water was made. Thereafter, 100ul of the aqueous extract were added to $2.0 \mathrm{ml}$ ABTS solution and the absorbances were measured at $734 \mathrm{~nm}$ after 15 mins in the dark, using LAB-Tech digital colorimeter, UK. The trolox equivalent antioxidant capacity was subsequently calculated as:

$$
\begin{aligned}
& \text { Trolox equivalent antioxidant capacity } \\
& \qquad=\% \text { sample } x \text { Conc of standard } x \stackrel{264.32}{\text { (Molarmass of Trolox) }}
\end{aligned}
$$

\section{Ferric Ion Reducing Antioxidant Power (FRAP) assay.}

The reducing property of the extracts was determined by assessing the ability of the extract to reduce $\mathrm{FeCl}_{3}$ solution as described by Oyaizu (1986). The extract (100ul) was mixed with $2.5 \mathrm{ml} 200 \mathrm{mM}$ sodium phosphate buffer (pH 6.6) and $2.5 \mathrm{ml} \mathrm{1 \%}$ potassium ferricyanide. The mixture was incubated at $50^{\circ} \mathrm{C}$ for $20 \mathrm{~min}$. and then $2.5 \mathrm{ml} 10 \%$ trichloroacetic acid was added. This mixture was centrifuged at $650 \mathrm{rpm}$ for $10 \mathrm{~min}$. Thereafter, $5 \mathrm{ml}$ of the supernatant were mixed with an equal volume of water and $1 \mathrm{ml} 0.1 \%$ ferric chloride. The absorbance was measured at 700 $\mathrm{nm}$ in the Lab-Tech digital colorimeter,UK. The ferric reducing antioxidant property was subsequently calculated as:

$$
\text { FRAP }=\frac{\text { Abs }_{\text {sample }} \times \text { Conc }_{\text {std }}}{\text { Abs }_{\text {std }} \times \text { Conc }_{\text {sample }}}
$$

\section{Determination of Total Phenol Content}

The total phenol content was determined according to the method of Singleton et al. (1999). The aqueous extracts $(100 \mathrm{ul})$ were oxidized with $2.5 \mathrm{ml} 10 \%$ FolinCiocalteau's reagent (v/v) and neutralized by $2.0 \mathrm{ml}$ of $7.5 \%$ sodium carbonate. The reaction mixture was incubated for 40 minute at $45^{\circ} \mathrm{C}$ and the absorbance was measured at $765 \mathrm{~nm}$ using a Lab-Tech digital colorimeter, UK. The total phenol content was subsequently calculated as gallic acid $(10 \mathrm{mg} / 100 \mathrm{ml})$ equivalent.

\section{Determination of Total Flavonoid Content}

The total flavonoid content was determined using a slightly modified method reported by Meda et al., (2005). The aqueous extract (100ul) was mixed with $0.5 \mathrm{ml}$ methanol, $50 \mu \mathrm{l} 10 \% \mathrm{AlCl}_{3}, 50 \mu \mathrm{l} 1 \mathrm{M}$ Potassium acetate and $1.4 \mathrm{ml}$ water, and allowed to incubate at room temperature for $30 \mathrm{~min}$. The absorbance of the reaction mixture was subsequently measured at 415 $\mathrm{nm}$ in the Lab-Tech digital colorimeter. The total flavonoid content was subsequently calculated using quercetin $(10 \mathrm{mg} / 100 \mathrm{ml})$ as standard the total

$$
\text { The total flavonoid }=\frac{A_{\text {sample }} \times \text { Conc }_{\text {std }}}{A_{\text {std }} \times \text { Conc }_{\text {sample }}}
$$

\section{Determination of Vitamin C}

Vitamin $C$ content of the aqueous extract was determined using the method of Benderitter et al., (1998). DNPH [2 g dinitrophenyl hydrazine, $230 \mathrm{mg}$ thiourea and $270 \mathrm{mg} \mathrm{CuSO} \mathrm{CH}_{2} .5 \mathrm{O}$ in $100 \mathrm{ml}$ of $5 \mathrm{M}$ 
$\mathrm{H}_{2} \mathrm{SO}_{4}$ ) was prepared and $75 \mu$ were added to 150 $\mu \mathrm{l}$ of the extracts and then $100 \mu \mathrm{l} 13.3 \%$ trichloroacetic acid (TCA) and water was added.

The reaction mixture was subsequently incubated for $3 \mathrm{~h}$ at $37{ }^{\circ} \mathrm{C}$, then $0.5 \mathrm{ml}$ of $65 \% \mathrm{H}_{2} \mathrm{SO}_{4}(\mathrm{v} / \mathrm{v})$ was added to the medium and the absorbance was measured at $520 \mathrm{~nm}$ in the Lab-Tech digital colorimeter, UK. The vitamin $C$ content of the extracts was subsequently calculated using ascorbic acid as standard $(10 \mathrm{mg} / 100 \mathrm{ml})$ as standard

$$
\text { Ascorbic Acid Content }=\frac{\text { Abs }_{\text {sample }} \times \text { Conc }_{\text {std }}}{\text { Abs }_{\text {std }} \times \text { Conc }_{\text {sample }}}
$$

Statistical Analysis

All experiments were carried out in triplicates. Results are expressed as mean \pm standard error of the means. Data were analyzed by Analysis of variance (ANOVA), and Duncan multiple range tests was used to assess the difference between groups while correlation study was used to assess the relationship of antioxidant and antioxidant scavenging abilities. Statistical significance was accepted at $P \leq 0.05$.

\section{RESULTS}

Total flavonoid, phenols and vitamin C content of Beetroot

Vitamin C, total flavonoid and phenol values obtained for the Beetroot samples are represented in Table 1. Heat treated beetroot had the highest flavonoid contents $(96.67 \pm 10.00 \mathrm{mg} / 100 \mathrm{ml})$. This value was significantly lower than that obtained for beetroot juice $(83.34 \pm 3.34 \mathrm{mg} / 100 \mathrm{ml})$. Oven dried beetroot having a value of $83.34 \pm 4.71 \mathrm{mg}$ Quercetin Equivalent $/ 100 \mathrm{ml}$ ) and beetroot juice were not significantly different in total flavonoid content. The raw beetroot had the lowest flavonoid content of $63.34 \pm 4.72 \mathrm{mg}$ Quercetin Equivalent $/ 100 \mathrm{ml}$ while Total phenol was highest for the raw beetroot and

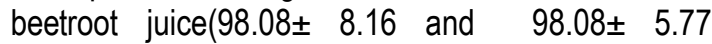
$\mathrm{mg} / \mathrm{GAE}$ ) respectively; with no significant difference at $(p>0.05)$.

The results revealed that Beetroot juice had the highest vitamin $C$ content $(44.34 \pm 2.8 \mathrm{AAEmg} / \mathrm{g})$ followed by the raw beetroot $(33.02 \pm 1.33 \mathrm{mgAAE} / \mathrm{g})$. The Beetroot juice have significantly higher amounts than raw beetroot at $p>0.05$. The heat treated and oven dried beetroot have the lowest value of vitamin C $(30.18 \pm 0.61$ and $31.14 \pm 1.34 \mathrm{AAEmg} / \mathrm{g})$ respectively. There was no significant $(p>0.05)$ in vitamin $C$ content for these two processed forms of beetroot.

\section{Antioxidant contents of the beetroot}

The results obtained for the in vitro antioxidant activity; ABTS scavenging ability and Ferric reducing antioxidant property (FRAP) of the beetroot are shown in Table 2. The heat treated and oven dried beetroot had the highest ABTS scavenging ability of $19.85 \pm 4.15 \mathrm{mmol} / \mathrm{g}$ and FRAP of $33.33 \pm 0.00 \mathrm{mg} / \mathrm{g}$ respectively. The heat treated beetroot had significantly $(p<0.05)$ higher ABTS scavenging abilities compared to the other beetroot samples. Similarly, the values obtained for the oven dried beetroot was significantly increased $\mathrm{P} \leq 0.5$ compared to other samples. Interestingly, the heat treated and oven dried beetroot exhibited a common trend in their scavenging properties respectively.

Table 1: Vitamin C, Total phenol and flavonoid content of Beetroot (Beta vulgaris)

\begin{tabular}{llll}
\hline Samples & Vitamin C $(\mathbf{m g ~ A A E} / \mathbf{g})$ & Total Flavonoid $(\mathbf{m g ~ Q E} / \mathbf{g})$ & Total Phenol $(\mathbf{m g ~ G A E} / \mathbf{g})$ \\
\hline Raw Beetroot & $33.02 \pm 1.33^{\mathrm{a}}$ & $63.34 \pm 4.72^{\dagger}$ & $98.08 \pm 8.16^{\mathrm{c}}$ \\
Beetroot juice & $44.34 \pm 2.84^{\mathrm{b}}$ & $83.34 \pm 3.34^{\mathrm{e}}$ & $98.08 \pm 5.77^{\mathrm{c}}$ \\
Heat treated Beetroot & $30.18 \pm 0.61^{\mathrm{ab}}$ & $96.67 \pm 10.00^{\mathrm{d}}$ & $96.15 \pm 0.00^{\mathrm{d}}$ \\
Oven dried Beetroot & $31.14 \pm 1.34^{\mathrm{ab}}$ & $83.34 \pm 4.71^{\mathrm{e}}$ & $94.23 \pm 2.72^{\mathrm{d}}$
\end{tabular}

Values are mean \pm standard error of the means of triplicate determinations

Mean values with different superscripts in the same column are significantly different at $p \leq 0.05$.

Table 2: Free radical scavenging abilities of the Beetroot (Beta vulgaris)

\begin{tabular}{lcc}
\hline Samples & $\begin{array}{c}\text { ABTS Scavenging ability } \\
(\mathbf{m m o l} / \mathbf{g})\end{array}$ & $\begin{array}{c}\text { Ferric Reducing } \\
\text { antioxidant property }(\mathbf{m g} / \mathbf{g})\end{array}$ \\
\hline Raw Beetroot & $11.33 \pm 0.00^{\mathrm{a}}$ & $16.67 \pm 0.00^{\mathrm{b}}$ \\
Beetroot juice & $11.94 \pm 1.71^{\mathrm{a}}$ & $20.84 \pm 4.17^{\mathrm{c}}$ \\
Heat treated Beetroot & $19.85 \pm 4.15^{\mathrm{b}}$ & $25.00 \pm 0.00^{\mathrm{d}}$ \\
Oven dried Beetroot & $11.75 \pm 1.37^{\mathrm{a}}$ & $33.33 \pm 0.00^{\mathrm{e}}$ \\
\hline
\end{tabular}

Values are mean + standard error of the means of triplicate determinations.

Mean values with different superscript are significantly different at $p<0.05$. 


\section{Correlation activity of beetroot}

Table 3 represents the correlation of beetroot total phenol, flavonoid and vitamin $\mathrm{C}$ with the antioxidant scavenging abilities. Ferric reducing ability has strong positive correlation with flavonoid and vitamin C (0.985 and 0.788 respectively) but was fairly correlated with total phenol $(0.360)$. ABTS was strongly positively correlated with total phenol and flavonoid positively. It was observed that Vitamin C correlated strongly positively with total phenol and flavonoid, ABTS and ferric acid reducing property (FRAP).

\section{DISCUSSION}

Beetroot (Beta vulgaris) is not a popularly consumed vegetable in Nigeria. The bulbous root is peeled, boiled and used in salads to give a reddish colour or mixed with other root vegetables and eaten with stew. It is also consumed by juicing the raw beetroots to make beetroot juice or combined with other fruit juices to make a mixed fruit juice (Wotton-Beard et al., 2011).Beetroot is widely grown in the Jos, Plateau State, Nigeria. Recently, it has become a part of the diet of the populace due to the westernisation of the diet of the Nigerian people. There is paucity in the literature about Nigerian Beetroots.

Beetroots have been reported to contain a high concentration of antioxidant compounds with capabilities for protective effects against DNA damage and oxidative stress (Vulić, et al., 2014). The potential role for beetroot as an adjuvant in the treatment in some clinical conditions involving oxidative stress and inflammation such as; hypertension, atherosclerosis, type 2 diabetes and dementia has been reported to be beneficial (Gilchrist, 2014; . Ninfali and Angelino, 2013). The red pigments in Beetroots are known as betalains which include betaxanthin, betacyanin (Lee et al., 2005).

The results of the study showed that Nigerian beetroots (raw and processed) are rich in vitamin C, total flavonoid and phenol. Their possible role as neutraceutical to prevent diseases sparked by oxidative stress may be abated by their ingestion. Flavonoids are natural polyphenols of plant origin. They have antioxidant, anti-inflammatory and anticarcinogenic properties (Bonaccorsi, et al., 2005).

The vitamin $\mathrm{C}$ content was highest in the beetroot juice. This makes it a potent natural drink to strengthen endogenous antioxidant defences and protect cellular damage. Wotton- beard and Ryan (2011), suggested that beetroot juice have good antioxidant scavenging abilities as determined by DPPH, FRAP and ABTS methods when compared to other fruit juices. However the values obtained by this present study of beetroots is much higher than those obtained from other Nigerian fruits (Oboh and Umoru, 2011). Juicing involves rupturing of the plant tissues which probably allowed more flavonoids and phenols to be released from the beetroots and could be responsible for the higher results obtained.

Table 3: Correlation of Total phenol, Total flavonoid, Vitamin C with Free radical scavenging abilities of the fruit extracts.

\begin{tabular}{|c|c|c|c|c|c|}
\hline & Total phenol & Total flavonoid & Vitamin C & $\begin{array}{l}\text { Ferric acid reducing } \\
\text { power (FRAP) }\end{array}$ & $\begin{array}{l}\text { ABTS Scavenging } \\
\text { Ability }\end{array}$ \\
\hline Total phenol & 1 & & & & \\
\hline Total flavonoid & 0.242 & 1 & & & \\
\hline Vitamin C & 0.731 & 0.772 & 1 & & \\
\hline $\begin{array}{l}\text { Ferric acid reducing } \\
\text { power (FRAP) }\end{array}$ & 0.360 & 0.985 & 0.78819 & 1 & \\
\hline ABTS Scavenging Ability & 0.589 & 0.517 & 0.87453 & 0.67952 & 1 \\
\hline
\end{tabular}

The increase in total phenol and flavonoid produced by heat treated and oven dried samples indicate that heat led to an increase in the quantity of antioxidant but vitamin $C$ was significantly reduced by heat. In general heat treatment and oven drying had a positive effect on flavonoids but not vitamin C. Vitamin $C$ is destroyed by heat as it becomes oxidized (Igwemmar et al., 2013). Total flavonoid in raw beetroot increased from 63.34 to 96.67 for heat treated and 83.34 for oven dried Beetroots.
Flavonoids contain C-glycoside bonds and exits as dimers and oligomers. (Aoyama, and Yamamoto, 2007) The heat processing may have resulted in the formation of monomers during the hydrolysis of $\mathrm{C}$ glycosides bonds. The results from this study is in agreement with those obtained with thermal heating of vegetables containing flavonoids. (Priecina and Karlina, 2013).The antioxidant activities of the processed beetroot as evaluated by ABTS and FRAP were increased at higher temperature. Oven dried 
had highest FRAP followed by heat treated. Similar results was reported by (Santas, 2008) in different Onion varieties. Previous findings (Manzocco et al., 2001; Gorinstein et al., 2008) have indicated that heating enhances antioxidant activity in fruits and vegetables due to the enhancement of the antioxidant property of the naturally occurring compounds or the formation of novel compounds that have antioxidant activity.

\section{CONCLUSION}

In this study, the raw and processed beetroots were found to have flavonoids, phenols vitamin $C$ and antioxidant scavenging abilities. The antioxidant and their scavenging abilities were positively correlated. The total flavonoids, phenols and their antioxidant scavenging abilities were increased by heat. Vitamin $C$ however was significantly reduced by heat.

\section{REFERENCES}

Aoyama, S. and Yamamoto, Y. (2007). Antioxidant activity and flavonoid content of Welsh onion (Allium fistulosum) and the effect of thermal treatment. Food Science Technology Research 13: 67-72.

Benderitter, M., Maupoil, V., Vergely, C., Dalloz, F., Briot, F., and Rochette, L. (1998). Studies by electron paramagnetic resonance of the importance of iron in the hydroxyl scavenging properties of ascorbic acid in plasma: Effects of iron chelators. Fundamentals Clinical Pharmacology, 12: 510-516.

Bonaccorsi, P., Caristi, C., Gargiulli, C. and Leuzzi, U. (2005). Flavonol glucoside profile of southern Italian red onion (Allium cepa L.). Journal of Agriculture and Food Chemistry; 53: 2733-2740.

Clifford, T., Howatson, G., West, D. J and Stevenson, E. J. (2015). The potential benefits of red beetroot supplementation in health and disease. Nutrients; 7(4): 2801-22.

Esatbeyoglu, T., Wagner, A. E., Schini-Kerth, V. B. and Rimbach, G. (2015). Betanin--a food colorant with biological activity. Molecular Nutrition and Food Research, 59(1): 36-47.

Georgiev, V., Weber, J., Kneschke, Eva-M., Petko, N. D., Bley. T.and Pavlov A. I. (2010) Antioxidant Activity and Phenolic Content of Betalain Extracts from Intact Plants and Hairy Root Cultures of the Red Beetroot Beta vulgaris cv. Detroit Dark Red. Plant Foods for Human Nutrition, 65(2): 105-111.

Gilchrist, M., Winyard, P. G., Fulford, J., Anning, C., Shore, A. C. and Benjamin, N. (2014). Dietary nitrate supplementation improves reaction time in type 2 diabetes: Development and application of a novel nitrate-depleted beetroot juice placebo. Nitric Oxide, 40: 67-74.

Gorinstein, S., Leontowicz, H. , Leontowicz, M., Namiesnik, J., Najman, K., Drzewiecki, J., Cvikrová , M.,Martincová,O., Katrich,E.and Trakhtenberg,S. (2008).Comparison of the main bioactive compounds and antioxidant activities in garlic and white and red onions after treatment protocols. Journal of Agriculture and Food Chemistry; 56: 4418-4426.

Grubben, G.J.H. and Denton, O.A. (2004). Plant resources of Tropical Africa 2. Vegetables. PROTA Foundation, Wageningen; Backhuys, Leiden;CTA, Wageningen, 94:14138-14143.

Hill, G and Langer, R.H.M. (1991). Agricultural plants. Cambridge, UK: Cambridge University Press. pp 197-199

Igwemmar, N.CS, Kolawole, S.A. and Imran, I.A. (2013). Effect of Heating on Vitamin C Content of Some Selected Vegetables. International Journal of Scientific and Technology Research, 2(11): 209-212.

Lechner, J.F., Wang, L.S., Rocha, C.M., Larue, B., Henry, C., Mclntyre, C. M., Riedl, K. M., Schwartz, S. J. and Stoner, G. D. (2010). Drinking water with red beetroot food color antagonizes esophageal carcinogenesis in $\mathrm{N}$ nitrosomethylbenzylamine-treated rats. Journal of Medicinal Food, 13(3): 733-739.

Lee, C .H., Wettasinghe, M., Bolling, B.W., Ji, L. L .and Parkin, K. L. (2005). Betalains, phase II enzyme-inducing components from red beetroot (Beta vulgaris L.) extracts. Nutrition and Cancer, 53: 91-103.

Lundberg, J.O., Weitzberg, E. and Gladwin, M.T. (2008). The nitrate-nitrite-nitric oxide pathway in physiology and therapeutics. Nature Reviews Drug Discovery, 7(2): 156-167.

Manzocco, L., Calligaris, S., Mastrocola, D., Nicoli, M.C. and Lerici, C.R. (2001). Review of non-enzymatic browning and antioxidant capacity in processed foods. Trends in Food Science and Technology, 11: 340-346.

Meda, A., Lamien, C.E., Romito, M., Millogo, J. and Nacoulma, O.G. (2005). Determination of the total phenolic, flavonoid and proline contents in Burkina Faso honey, as well as their radical scavenging activity. Food Chemistry, 91: 571577.

Ninfali, P. and Angelino, D. (2013). Nutritional and functional potential of Beta vulgaris cicla and rubra. Fitoterapia; 89: 188-199.

Oboh, H. A and Umoru, A. I. (2011). Total phenolics, Vitamin $C$ and free radical scavenging capacities of some Nigerian Fruits. Nigerian 
Journal of Biochemistry and Molecular Biology. 26(1): 67-75.

Oyaizu, M. (1986). Studies on products of browning reaction: antioxidative activity of products of browning reaction prepared from glucosamine. The Japanese Journal of Nutrition and Dietetics, 44: 307-315.

Priecina, L. and Karlina, D. (2013). Total polyphenol, flavonoid content and antiradical activity of celery, dill, parsley. Onion and garlic dried in convective and microwave-vacuum dryers. 2nd International Conference on Nutrition and Food Sciences IPCBEE, vol. 53, IACSIT Press, Singapore.

Rabeh, N. M. (2015). Effect of Red Beetroot (Beta vulgaris $L$.) And its Fresh Juice Against Carbon Tetrachloride Induced Hepatotoxicity in Rats. World Applied Sciences Journal, 33(6): 931938.

Re, R., Pellegrini, N., Proteggente, A., Pannala, A., Yang, M. and Rice-Evans, C (1999). Antioxidant activity applying an improved ABTS radical cation decolorization assay. Free Radical Biology and medicine, 26(9): 1231-1237.

Santas, J., Carbó R., Gordon , M. H. and Almajanoc, M. P. (2008). Comparison of the antioxidant activity of two Spanish onion varieties. Food Chemistry, 107: 1210-1216.

Singleton, V.L., Orthofor, R. and Lamuela Raventos, R.M (1999). Analysis of total phenols and other oxidation substrates and antioxidants by means of Folin-Ciocaltau reagent. Methods. Enzymology, 299: $152-178$.
Strack, D., Vogt, T. and Schliemann W. (2003). Recent advances in betalain research. Phytochemistry; 62: 247-269.

Straus, S., Bavec, F., Turinek, M., Slatnar, A., Rozman, C. and Bavec, M. (2012. Nutritional value and economic feasibility of red beetroot (Beta vulgaris L. ssp. vulgaris Rote Kugel) from different production systems. African Journal of Agricultural Research, 7(42): 5653-5660.

Vulić, J. J., Ćebović, T. N., Čanadanović-Brunet, J. M., Ćetković, G. S., Čanadanović, V.M., Djilas, S. M. and Tumbas Šaponjac, V. T. (2014). In vivo and in vitro antioxidant effects of beetroot pomace extracts. Journal of Functional Foods, 6: 168-175.

Wootton-Beard, P. C., Brandt, K., Fell, D., Warner, S. and Ryan, L. (2011b). Effects of a beetroot juice with high neobetanin content on the early-phase insulin response in healthy volunteers. Journal of Nutritional Science, 3: 1-9.

Wootton-Beard, P.C. and Ryan, L. (2011a). A beetroot juice shot is a significant and convenient source of bioaccessible antioxidants. Journal of Functional Foods, 3: 329-334.

Zhang, Q., Pan, J., Wang, Y., Lubet, R. and You, M. (2013). Beetroot red (betanin) inhibits vinyl carbamate- and benzo(a)pyrene-induced lung tumorigenesis through apoptosis. Molecular Carcinogenesis, 52(9): 686-691.

Zielinska-Przyjemska, M., Olejnik, A. DobrowolskaZachwieja, A. and Grajek, W. (2009) . In vitro effects of beetroot juice and chips on oxidative metabolism and apoptosis in neutrophils from obese individuals. Phototherapy Research; 23(1): 49-55. 